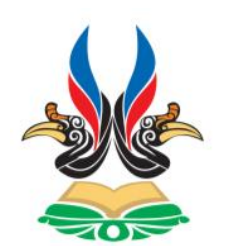

SPECTA Journal of Technology

E-ISSN : 2622-9099

P-ISSN : 2549-2713

Homepage jurnal: https://journal.itk.ac.id/index.php/sjt

\title{
Evaluasi Sistem Drainase Kawasan Kampus Institut Teknologi Kalimantan (ITK) Balikpapan (Studi Kasus: Fakultas MIPA)
}

\author{
Rossana Margaret Kadar Yanti ${ }^{1}$, Achmad Ghozali ${ }^{2}$, Muhammad Alif Firdaus ${ }^{3}$ \\ ${ }^{1,3}$ Program Studi Teknik Sipil, Fakultas Teknik Sipil dan Perencanaan, Institut Teknologi Kalimantan, Jl. \\ Soekarno Hatta KM.15, Balikpapan, Kalimantan Timur. Email:07161049@student.itk.ac.id \\ ${ }^{2}$ Program Studi Perencanaan Wilayah dan Kota, Fakultas Teknik Sipil dan Perencanaan, Institut Teknologi \\ Kalimantan, Jl. Soekarno Hatta KM.15, Balikpapan, Kalimantan Timur.
}

\begin{abstract}
The development of Kalimantan Institute of Technology (ITK) area has resulted in changes of land use and increasing the drainage coefficient values (c). This condition is directly proportional to the increase of runoff debit value (hydrological). Based on this condition, it is necessary to conduct an evaluation related to the existing drainage system at MIPA Faculty area of ITK to determine the capacity of the canal in flowing runoff (hydrological) that occurs. In this research, a hydrological analysis was conducted to calculate the peak of discharge at MIPA Faculty area by using a rational method and a hydraulic analysis to determine the capacity of the existing canal using the Manning method. The purpose of this analysis is to determine the comparison between hydrological discharge and the canal capacity of MIPA Faculty. The results of the analysis show that runoff discharge that occur at MIPA Faculty area have varying values between $0.007 \mathrm{~m}^{3} / \mathrm{sec}$ to $0.300 \mathrm{~m}^{3} / \mathrm{sec}$. In the drainage system of MIPA Faculty area, there are 7 tertiary canals, 8 secondary canals and 2 primary canals which have overcapacity that cause overflow. Overflow discharge that occurs in MIPA Faculty area varies from 0.001 $\mathrm{m}^{3} / \mathrm{sec}$ to $0.163 \mathrm{~m}^{3} / \mathrm{sec}$.
\end{abstract}

Keywords: drainage system, evaluation, MIPA faculty of ITK.

\begin{abstract}
Abstrak
Pembangunan kawasan kampus Institut Teknologi Kalimantan mengakibatkan perubahan fungsi lahan dan meningkatkan nilai koefisien pengaliran (c). Kondisi ini berbanding lurus dengan peningkatan nilai debit limpasan (hidrologi). Berdasarkan kondisi ini, maka perlu dilakukan evaluasi terkait sistem drainase eksisting pada Fakultas MIPA ITK untuk mengetahui kapasitas saluran dalam mengalirkan debit limpasan (hidrologi) yang terjadi. Dalam penelian ini dilakukan analisis hidrologi untuk menghitung debit puncak pada Fakultas MIPA dengan menggunakan metode rasional dan analisis hidrolika untuk mengetahui kapasitas saluran eksisting dengan menggunakan metode manning. Analisis ini bertujuan untuk mengetahui perbandingan antara debit hidrologi dengan kapasitas saluran Fakultas MIPA. Hasil analisis didapatkan debit limpasan yang terjadi pada Fakultas MIPA memiliki nilai yang bervariasi antara 0,007 $\mathrm{m}^{3} /$ detik hingga 0,300 $\mathrm{m}^{3} /$ detik. Dalam sistem drainase Fakultas MIPA terdapat 7 saluran tersier, 8 saluran sekunder dan 2 saluran primer yang mengalami kelebihan kapasitas sehingga terjadi luapan. Debit luapan yang terjadi pada kawasan Fakultas MIPA bervariasi mulai dari 0,001 m3/detik hingga 0,163 $\mathrm{m}^{3} /$ detik.
\end{abstract}

Kata Kunci: evaluasi, fakultas MIPA ITK, sistem drainase. 


\section{Pendahuluan}

Kampus Institut Teknologi Kalimatan (ITK) terletak di Kota Balikpapan tepatnya di wilayah Karang Joang. Diresmikan oleh Presiden Susilo Bambang Yudhoyono pada tanggal 6 Oktober 2019, kampus ini memiliki dua gedung perkuliahan bersama yaitu gedung A dan B dengan luas $48000 \mathrm{~m}^{2}$. ITK mulai beroperasi pada tahun 2015 dengan 263 mahasiswa dalam 10 program studi. Dua gedung perkuliahan yang telah dibangun menjadi pusat seluruh kegiatan mahasiswa, baik kegiatan belajar mengajar, kegiatan keagamaan hingga kegiatan kemahasiswaan. Seiring dengan berjalannya waktu, pengembangan sarana dan prasarana pada kawasan fakultas MIPA mulai direncanakan.

Pengembangan kawasan Fakultas MIPA dilakukan sebagai bentuk dan upaya pemenuhan sarana dan prasarana penunjang kegiatan belajar mengajar. Pengembangan dimulai dengan pembangunan lahan parkir pada area gedung A dan gedung B Institut Teknologi Kalimantan. Pengembangan dilanjutkan dengan pembangunan satu buah masjid sebagai sarana dan prasarana kegiatan keagamaan serta beberapa kawasan di sekitar gedung A dan gedung B yang dikembangkan menjadi taman dan ruang terbuka hijau (RTH). Pengembangan juga dilakukan pada sarana kegiatan belajar mengajar dengan membangun satu gedung perkuliahan baru yakni gedung $\mathrm{C}$ pada kawasan Fakultas MIPA. Berikut merupakan tampak pengembangan kawasan Fakultas MIPA dari tahun ke tahun yang ditunjukkan pada Gambar 1.

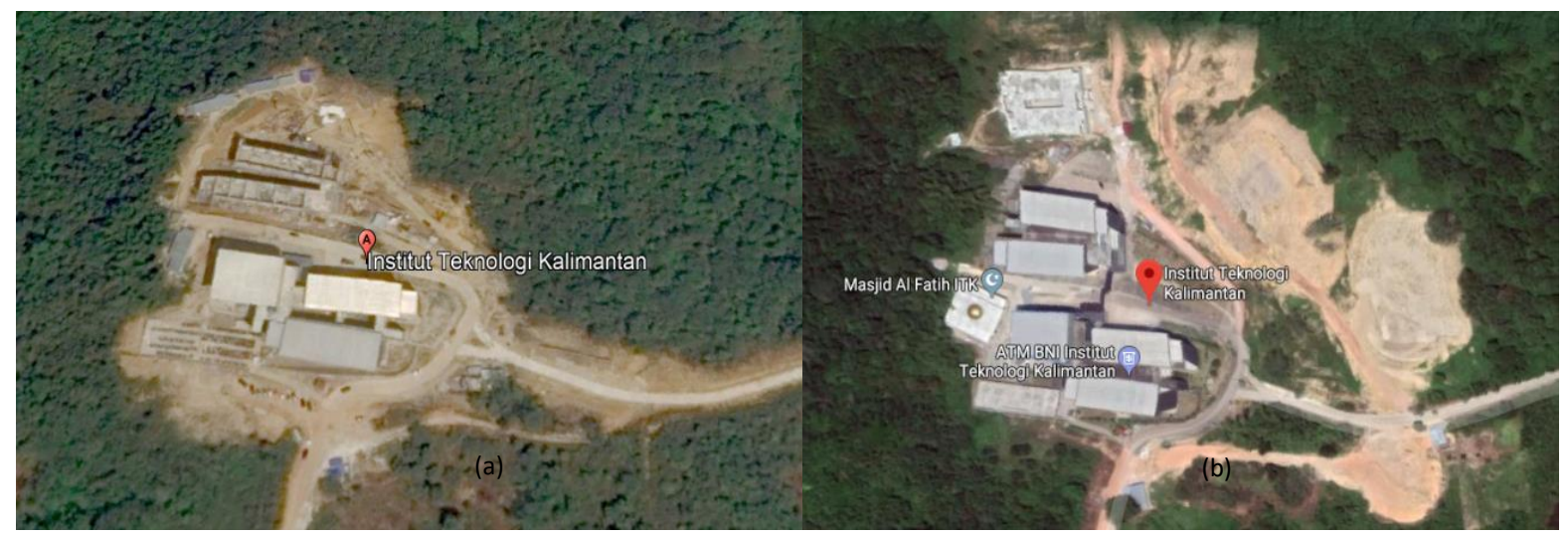

Gambar 1: (a) Kondisi Lahan ITK pada tahun 2015; (b) Kondisi Lahan ITK pada tahun 2019 Sumber: Google earth, 2019

Gambar 1 menunjukkan bahwa pengembangan kawasan fakultas MIPA mengubah tutupan lahan, dari yang semula merupakan tutupan lahan hijau menjadi terbangun. Kondisi ini berpengaruh terhadap perubahan koefisien pengaliran di kawasan. Hal ini mengakibatkan pada peningkatan nilai debit limpasan (hidrologi) kawasan Fakultas MIPA ITK. Meningkatnya nilai debit limpasan (hidrologi) kawasan akan berpengaruh pada kapasitas saluran drainase eksisting kawasan. Hal inilah yang menjadi latar belakang perlu dilakukannya evaluasi kapasitas saluran terhadap peningkatan debit hidrologi yang terjadi akibat perubahan fungsi lahan pada kawasan Fakultas MIPA ITK (Anggraini, 2016).

Tujuan dari penelitian ini adalah untuk mengetahui nilai debit limpasan (hidrologi) yang terjadi pada kawasan Fakultas MIPA ITK setelah terjadinya perubahan fungsi lahan. Nilai debit ini kemudian akan dibandingkan dengan besar kapasitas saluran drainase untuk diperoleh hasil selisih antara debit limpasan (hidrologi) dengan kapasitas saluran (hidrolika). Dengan demikian akan diketahui apakah saluran drainase kawasan Fakultas MIPA masih mampu mengalirkan debit limpasan akibat hujan tanpa adanya luapan.

\section{Metodologi}

Sistematika dalam pelaksanaan penelitian terkait evaluasi saluran drainase kampus ITK Balikpapan (Studi kasus: Fakultas MIPA ITK) adalah sebagai berikut: 


\subsection{Identifikasi Masalah}

Identifikasi masalah merupakan tahapan untuk mengetahui permasalahan yang terjadi pada sistem drainase kawasan Fakultas MIPA ITK. Tahapan ini bertujuan untuk mengetahui langkah penelitan yang dilakukan untuk mencapai tujuan yang telah ditentukan. Dengan identifikasi masalah akan membantu dalam proses penyusunan alternatif solusi.

\subsection{Tahap Persiapan}

Tahap persiapan dilakukan untuk mengetahui gambaran kondisi dan lokasi Fakultas MIPA ITK secara umum. Tahap persiapan dilakukan dengan serangkaian kegiatan yaitu survei kondisi lapangan dan studi literatur yang bertujuan untuk menunjang pelaksanaan penilitian. Survei lapangan merupakan kelanjutan dari studi literatur dimana pengumpulan data didapatkan melalui tinjauan langsung ke lokasi perencanaan dan meninjau secara langsung kondisi eksisting saluran dan kawasan perencanaan. Dalam kegiatan survei lapangan akan dilakukan pengumpulan data primer yang dibutuhkan. Survei yang dilakukan dalam tugas akhir ini meliputi gedung-gedung dan saluran yang telah terbangun pada kawasan Institut Teknologi Kalimantan.

\subsection{Pengumpulan Data}

Pengumpulan data dilakukan untuk memperoleh secara spesifik terkait kondisi dan permasalahan yang terjadi di Fakultas MIPA ITK. Pengumpulan data diperoleh dari berbagai sumber, yaitu:

1. Badan Meteorologi, Klimatologi dan Geofisika (BMKG) Kota Balikpapan yang berupa data curah hujan maksimum tahunan.

2. Divisi Sub Bagian Perencanaan Institut Teknologi Kalimantan berupa Peta Topografi dan Masterplan pembangunan Kampus Institut Teknologi Kalimantan.

\subsection{Analisis Hidrologi}

Analisis hidrologi terdiri dari analisis curah hujan dan analisis debit banjir. Pada tahap analisis hujan rencana, dilakukan perhitungan curah hujan maksimum tahunan untuk mendapatkan besar curah hujan periode ulang pada lokasi studi. Hasil perhitungan curah hujan periode ulang kemudian digunakan sebagai tahapan awal untuk memperoleh besar debit yang melimpas pada sistem drainase kawasan Fakultas MIPA ITK.

\subsection{Analisis Hidrolika}

Analisis hidrolika dilakukan untuk menghitung kapasitas saluran eksisting pada Fakultas MIPA ITK yang dapat menampung debit yang mengalir pada saluran. Analisis hidrolika merupakan analisis kondisi limpasan air yang berada pada saluran sistem drainase yang harus mampu menampung debit limpasan pada analisis hidrologi. Analisis hidrolika dilakukan adalah sebagai berikut:

1. Perhitungan kapasitas saluran pada sistem drainase berdasarkan debit hidrologi harus lebih kecil dari debit hidrolika.

2. Penentuan koefisien kekasaran saluran menggunakan rumus Manning.

3. Perencanaan dimensi saluran dengan memperhitungkan debit maksimum.

\subsection{Evaluasi Kinerja Saluran}

Evaluasi kinerja saluran merupakan tahap membandingkan debit hidrologi rencana dengan kapasitas saluran. Dari hasil perbandingan diperoleh hasil kinerja dari saluran eksisting Fakultas MIPA ITK. Kinerja yang diukur dalam tahapan ini berkaitan dengan kapasitas saluran drainase dalam mengalirkan debit limpasan (hidrolologi) tanpa adanya luapan.

\subsection{Kesimpulan}

Kesimpulan merupakan deskripsi singkat dari hasil pembahasan terkait evaluasi kinerja saluran pada Fakultas MIPA ITK. Kesimpulan memuat tujuan dan hasil analisis dalam penelitian ini yang disajikan secara ringkas dan jelas.

Langkah-langkah pelaksanaan evaluasi kinerja saluran Fakultas MIPA ITK dapat dilihat pada Gambar 2 berikut: 


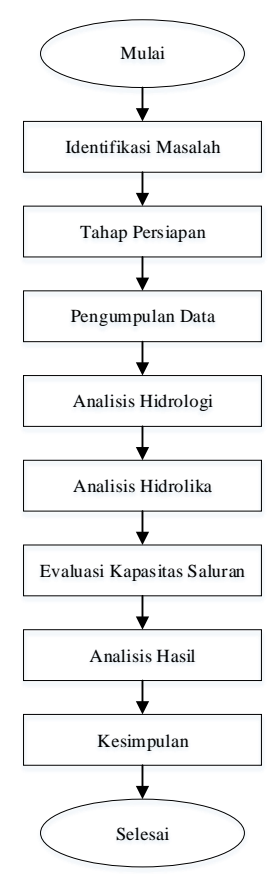

Gambar 2: Diagram Alir Studi Sumber: Penulis, 2020

\section{Hasil dan Pembahasan}

\subsection{Lokasi Perencanaan}

Lokasi evaluasi berada di kawasan Kampus Institut Teknologi Kalimantan (ITK) Jalan Karang Joang kilometer 15 Kota Balikpapan dan secara spesifiknya evaluasi sistem drainase dilakukan pada salah satu cluster pendidikan di Institut Teknologi Kalimatan yaitu cluster Fakultas MIPA. Fakultas MIPA dibangun di lahan seluas 10 hectare (ha) dengan dua gedung utama yaitu gedung A dan B dengan luas $48000 \mathrm{~m}^{2}$ dan satu gedung perkuliahan yaitu gedung $\mathrm{C}$ dengan luas bangunan $1800 \mathrm{~m}^{2}$. Berikut merupakan denah dari Fakultas MIPA ITK (Gambar 3). 


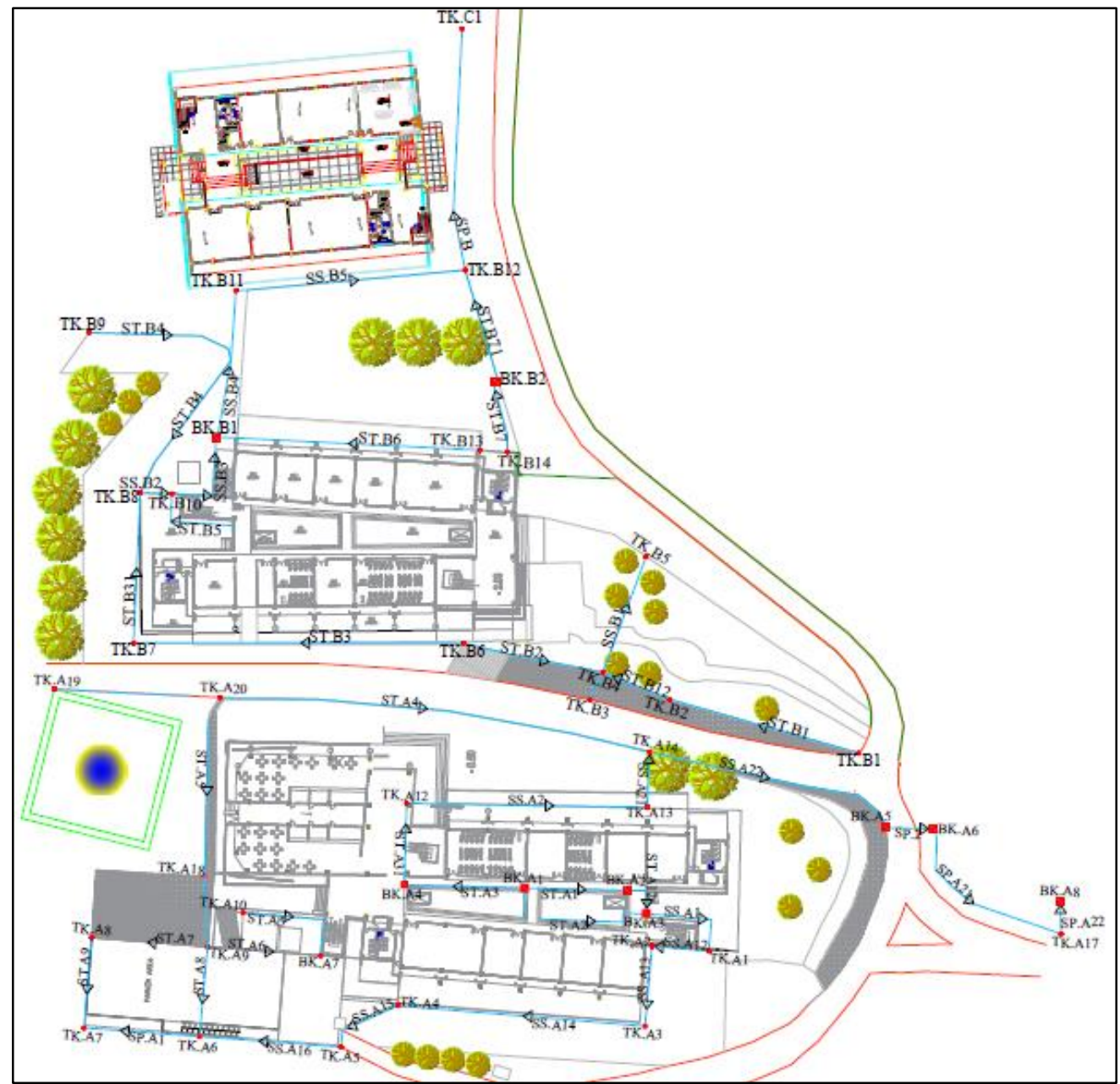

Gambar 3: Denah Kawasan Fakultas MIPA ITK

Sumber: Divisi sub bagian perencanaan ITK, 2018

Gambar 3 merupakan denah kawasan penelitian dan arah aliran dalam saluran drainase. Denah dan arah aliran ini berfungsi untuk mengidentifikasi arah aliran air sebelum menuju ke badan air (saluran buangan akhir).

\subsection{Analisis Hidrologi}

Analisis debit limpasan (hidrologi) seperti yang telah dijelaskan sebelumnya merupakan langkah awal dalam proses evaluasi dan perencanaan ulang saluran. Dalam menganalisis debit hidrologi dibutuhkan data curah hujan maksimum tahunan. Data curah hujan yang digunakan dalam penelitian ini merupakan data curah hujan yang diperoleh dari stasiun meteorologi Sultan Aji Muhammad Sulaiman (SAMS) Sepinggan Balikpapan. Data yang digunakan hanya berasal dari satu stasiun hujan karena pada lokasi tinjauan, yakni Kota Balikpapan hanya memiliki satu stasiun hujan. Data hujan yang dikumpulkan merupakan data curah hujan selama 10 tahun yakni tahun 2010 - 2019. Berikut merupakan data curah hujan yang diperoleh dari stasiun meteorologi SAMS Sepinggan Balikpapan pada Tabel 1. 
Tabel 1: Data curah hujan maksimum tahunan Kota Balikpapan

\begin{tabular}{ll}
\hline \multicolumn{1}{c}{ Tahun } & \multicolumn{1}{c}{ Curah Hujan Maksimal Tahunan } \\
$(\mathbf{m m})$
\end{tabular}

Tabel 1 merupakan data tinggi hujan maksimum harian yang diambil tiap tahun dimulai dari tahun 2010 hingga 2019. Data hujan ini merupakan salah satu varibel yang digunakan dalam analisis debit limpasan (hidrologi). Jumlah data curah hujan maksimum harian yang dapat digunakan untuk analisis debit adalah sebanyak sepuluh data. Dengan demikian, maka jumlah data dan jenis data pada Tabel 1 dapat digunakan untuk analisis debit.

\subsubsection{Analisis Curah Hujan Periode Ulang}

Dalam penelitian ini, analisis curah hujan periode ulang menggunakan persamaan distribusi Normal (Triadmodjo, 2008). Perhitungan curah hujan menggunakan persamaan distribusi Normal adalah sebagai berikut:

$$
X=\bar{X}+\left(K_{T} \times S\right)
$$

Di mana:

$X \quad$ : Perkiraan nilai yang diharapkan terjasi dengan periode ulang T-tahunan (mm);

$\bar{X} \quad$ : Curah hujan rata-rata hitung $(\mathrm{mm})$;

$S \quad$ : Deviasi standar; dan

$K_{T}$ : Nilai reduksi Gauss yakni faktor sifat dari Distribusi Normal yang merupakan faktor dari peluang dan periode ulang.

Dari perhitungan, diperoleh nilai:

$\bar{X}=129,27 \mathrm{~mm}$ dan $S=37,882$.

Diperoleh nilai curah hujan periode ulang pada Tabel 2 sebagai berikut:

Tabel 2: Nilai curah hujan periode ulang

\begin{tabular}{lllll}
\hline $\begin{array}{c}\text { Periode Ulang } \\
\text { (Tahun) }\end{array}$ & \multicolumn{1}{c}{$\bar{X}(\mathbf{m m})$} & \multicolumn{1}{c}{ Faktor Distribusi } & \multicolumn{1}{c}{$\boldsymbol{S}$} & \multicolumn{1}{c}{$\boldsymbol{X}(\mathbf{m m})$} \\
\hline 2 & 129,27 & 0 & 37,882 & 129,270 \\
5 & 129,27 & 0,84 & 37,882 & 161,091 \\
10 & 129,27 & 1,28 & 37,882 & 177,760 \\
\hline
\end{tabular}

Sumber: Hasil Analisis, 2020

Hasil dari perhitungan nilai curah hujan periode ulang akan digunakan untuk melakukan analisis debit hidrologi dalan evaluasi sistem drainase kawasan Fakultas MIPA ITK. Digunakan curah hujan periode ulang 2, 5, dan 10 tahunan sebagai dasar analisis debit hidrologi yang mengalir pada masing-masing saluran Fakultas MIPA ITK. Periode ulang 2 tahun digunakan untuk jenis saluran tersier, periode ulang 5 tahun untuk jenis saluran sekunder, dan periode ulang 10 tahun untuk jenis saluran primer. 


\subsubsection{Analisis Debit Banjir Rencana}

Analisis debit banjir Fakultas MIPA ITK dihitung dengan menggunakan metode rasional dengan menggunakan persamaan berikut:

$$
Q=0.278 \times C \times I \times A
$$

Di mana:

$Q \quad$ : Debit puncak yang ditimbulkan oleh hujan dengan intensitas, durasi dan frekuensi tertentu $\left(\mathrm{m}^{3} / \mathrm{det}\right)$;

$I \quad: \quad$ Intensitas curah hujan $(\mathrm{mm} / \mathrm{jam})$;

$A \quad$ : Luas daerah tangkapan $\left(\mathrm{km}^{2}\right)$; dan

$C \quad$ : Koefisien aliran yang tergantung pada jenis permukaan lahan.

Hasil dari perhitungan dengan metode rasional akan menghasilkan nilai debit limpasan yang akan digunakan sebagai variabel untuk melakukan evaluasi kapasitas terhadap jaringan drainase yang ada pada Fakultas MIPA. Nilai debit limpasan akan dibandingkan dengan nilai dari kapasitas penampang yang akan didapatkan pada perhitungan analisis hidrolika saluran.

Nilai intensitas dapat dihitung dengan menggunakan persamaan Mononobe sebagai berikut:

$$
I=\frac{R_{24}}{24} \times\left(\frac{24}{T_{c}}\right)^{2 / 3}
$$

Di mana:

I : Intensitas curah hujan ( $\mathrm{mm} / \mathrm{jam})$;

$T_{c} \quad$ : Waktu konsentrasi hujan (jam); dan

$R_{24} \quad$ : Curah hujan maksimum dalam 24 jam (mm).

Nilai intensitas hujan $(I)$ merupakan salah satu variabel yang digunakan dalam menganalisis besar debit limpasan $(Q)$ dalam analisis hidrologi. Nilai intensitas $(I)$ berpengaruh terhadap lama hujan harian yang terjadi di Fakultas MIPA.

Waktu pengaliran pada lahan $\left(t_{0}\right)$.

Persamaan yang digunakan untuk mendapatkan lamanya pengaliran pada tanah menggunakan persamaan Kirby adalah sebagai berikut (Suripin, 2004):

$$
t_{0}=1.44 \times\left(n d \times \frac{l}{\sqrt{s}}\right)^{0.467}
$$

Di mana:

$l \quad: \quad$ Jarak dari titik terjauh menuju inlet di mana $1<400 \mathrm{~m}(\mathrm{~m})$;

nd : Koefisien setara koefisien kekasaran; dan

$s \quad$ : Kemiringan medan.

Hasil dari perhitungan $t_{0}$ akan digunakan sebagai salah satu variabel untuk mengetahui waktu konsentrasi $\left(t_{c}\right)$ pada kawasan Fakultas MIPA ITK. Nilai $t_{0}$ berpengaruh terhadap jarak dari lahan menuju ke inlet terdekat dan kemiringan dari lahan tersebut. Nilai kekasaran dari suatu lahan juga berpengaruh terhadap perhitungan nilai $t_{0}$. 
Waktu pengaliran pada saluran $\left(t_{f}\right)$.

Persamaan yang digunakan untuk mendapatkan waktu yang dibutuhkan oleh limpasan pada saluran mengalir dari suatu titik ke titik lainnya menggunakan persamaan sebagai berikut:

$$
t_{f}=\frac{L}{V}
$$

Di mana:

$L \quad$ : Panjang saluran lintasan limpasan (m);

$V \quad: \quad$ Kecepatan aliran limpasan dalam saluran (m/detik).

Waku pengaliran pada saluran $\left(t_{f}\right)$ merupakan salah satu variabel dalam perhitungan waktu konsentrasi $\left(t_{c}\right)$. Nilai $t_{f}$ merupakan waktu limpasan mengalir pada saluran menuju ke titik tinjauan terdekat. Nilai $t_{f}$ dipengaruhi oleh panjang saluran dan kecepatan dari aliran yang melimpas.

Waktu Konsentrasi $\left(t_{c}\right)$ adalah waktu yang diperlukan oleh limpasan hujan untuk mengalir dari titik terjauh (titik jatuhnya hujan) menuju titik kontrol. Waktu konsentrasi terbagi menjadi dua yakni waktu pengaliran untuk lahan atau overland flow $\left(t_{0}\right)$ dan waktu pengaliran pada saluran $\left(t_{f}\right)$. Didapatkan persamaan untuk menentukan waktu konsentrasi adalah sebagai berikut (Soemarto, 1999):

$$
t_{c}=t_{0}+t_{f}
$$

Di mana:

$t_{c} \quad$ : Waktu konsentrasi (detik);

$t_{0} \quad$ : Waktu pengaliran pada permukaan (detik); dan

$t_{f} \quad$ : Waktu pengaliran pada saluran (detik).

Waktu konsentrasi $\left(t_{c}\right)$ akan digunakan pada perhitungan intensitas hujan. Nilai $t_{c}$ merupakan penjumlahan waktu pengaliran pada lahan $\left(t_{0}\right)$ dan waktu pengaliran pada saluran $\left(t_{f}\right)$ yang masuk pada suatu titik kontrol.

Koefisien Pengaliran ( $C$ ) dihitung dengan persamaan berikut (Triadmodjo, 2008):

$$
C_{g a b}=\frac{\sum C_{i} \times A_{i}}{\sum A}
$$

Di mana:

$C_{g a b}:$ Nilai koefisien pengaliran rata-rata atau gabungan;

$C_{i} \quad: \quad$ Koefisien pengaliran untuk bagian daerah yang ditinjau dengan satu jenis permukaan lahan;

$A_{i} \quad:$ Luas bagian daerah aliran.

Nilai $C$ merupakan nilai koefisien pengaliran pada suatu lahan yang bergantung pada jenis tutupan lahan tersebut. $C_{g a b}$ merupakan penjumlahan nilai $C$ dari lahan yang masuk ke inlet yang dikalikan dengan 
luas lahan dengan satu jenis permukaan lahan. Nilai $C$ akan digunakan dalam perhitungan untuk mendapatkan debit limpasan yang akan membebani jaringan drainase Fakultas MIPA.

Berdasarkan persamaan-persamaan tersebut, didapatkan hasil perhitungan debit hidrologi pada kawasan Fakultas MIPA ITK yang dapat dilihat pada Tabel 3.

Tabel 3: Debit hidrologi kawasan Fakultas MIPA ITK

\begin{tabular}{|c|c|c|c|c|c|c|}
\hline Titik Kontrol & Nama Saluran & $T_{c}(\mathbf{j a m})$ & $C_{g a b}$ & $A\left(\mathbf{k m}^{2}\right)$ & $I(\mathbf{m m} / \mathbf{j a m})$ & $Q_{\text {hidrologi }}\left(\mathrm{m}^{3} / \mathrm{dt}\right)$ \\
\hline BK.A1-BK.A2 & ST.A1 & 0,120 & 0,950 & 0,0004 & 184,490 & 0,018 \\
\hline BK.A2-BK.A3 & ST.A12 & 0,140 & 0,950 & 0,0005 & 166,100 & 0,021 \\
\hline TK.A18-TK.A9 & ST.A10 & 0,040 & 0,950 & 0,0003 & 393,320 & 0,035 \\
\hline TK.А9-ТK.А6 & ST.A8 & 0,060 & 0,940 & 0,0004 & 292,320 & 0,028 \\
\hline TK.А9-TK.А8 & ST.A7 & 0,040 & 0,900 & 0,0003 & 416,900 & 0,027 \\
\hline TK.A8-TK.A7 & ST.A9 & 0,050 & 0,900 & 0,0004 & 318,200 & 0,033 \\
\hline BK.A1'-BK.A4 & ST.A3 & 0,140 & 0,950 & 0,0004 & 163,970 & 0,018 \\
\hline BK.A4-TK.A12 & ST.A31 & 0,170 & 0,950 & 0,0008 & 148,410 & 0,032 \\
\hline TK.A20-TK.14 & ST.A4 & 0,140 & 0,940 & 0,0014 & 164,970 & 0,061 \\
\hline TK.B1-TK,B2 & ST.B1 & 0,050 & 0,930 & 0,0003 & 342,780 & 0,022 \\
\hline TK.B2-TK.B4 & ST.B12 & 0,060 & 0,920 & 0,0003 & 295,630 & 0,025 \\
\hline TK.B3-TK.B4 & ST.B13 & 0,060 & 0,950 & 0,0001 & 294,640 & 0,009 \\
\hline TK.B6-TK.B4 & ST.B2 & 0,070 & 0,900 & 0,0001 & 267,860 & 0,007 \\
\hline TK.B6-TK.B7 & ST.B3 & 0,060 & 0,900 & 0,0005 & 283,130 & 0,034 \\
\hline TK.B7-TK.B8 & ST.B31 & 0,080 & 0,900 & 0,0007 & 244,510 & 0,043 \\
\hline TK.В9-ТK.В8 & ST.B4 & 0,030 & 0,900 & 0,0005 & 466,560 & 0,053 \\
\hline TK.B13-BK.B1 & ST.B6 & 0,030 & 0,950 & 0,0001 & 446,960 & 0,009 \\
\hline TK.B14-BK.B2 & ST.B7 & 0,020 & 0,950 & 0,0001 & 690,910 & 0,009 \\
\hline BK.B2-TK.B12 & ST.B71 & 0,030 & 0,900 & 0,0003 & 465,430 & 0,038 \\
\hline BK.A3-TK.A1 & SS.A1 & 0,140 & 0,970 & 0,0008 & 204,879 & 0,041 \\
\hline TK.A1-TK.A2 & SS.A12 & 0,150 & 0,920 & 0,0008 & 197,852 & 0,041 \\
\hline TK.A2-TK.A3 & SS.A13 & 0,160 & 0,860 & 0,0011 & 186,762 & 0,048 \\
\hline TK.A3-TK.A4 & SS.A14 & 0,210 & 0,710 & 0,0015 & 155,647 & 0,049 \\
\hline TK.A4-TK.A5 & SS.A15 & 0,220 & 0,780 & 0,0016 & 153,042 & 0,049 \\
\hline TK.A5-TK.А6 & SS.A16 & 0,250 & 0,740 & 0,0021 & 141,481 & 0,063 \\
\hline TK.A12-TK.13 & SS.A2 & 0,190 & 0,950 & 0,0010 & 167,628 & 0,045 \\
\hline TK.A13-TK.A4 & SS.A21 & 0,200 & 0,910 & 0,0011 & 162,441 & 0,045 \\
\hline TK.A14-BK.A5 & SS.A22 & 0,220 & 0,880 & 0,0029 & 124,215 & 0,089 \\
\hline TK.B4-TK.B5 & SS.B1 & 0,070 & 0,820 & 0,0007 & 259,789 & 0,039 \\
\hline TK.B8-TK.B10 & SS.B2 & 0,080 & 0,870 & 0,0012 & 236,114 & 0,069 \\
\hline TK.B10-BK.B1 & SS.B3 & 0,130 & 0,900 & 0,0032 & 176,430 & 0,143 \\
\hline BK.B1-TK.B11 & SS.B4 & 0,130 & 0,900 & 0,0035 & 171,221 & 0,149 \\
\hline TK.B11-TK.B12 & SS.B5 & 0,140 & 0,900 & 0,0050 & 166,927 & 0,208 \\
\hline
\end{tabular}




\begin{tabular}{lllllll}
\hline \multicolumn{1}{c}{ Titik Kontrol } & Nama Saluran & $\boldsymbol{T}_{\boldsymbol{c}}(\mathbf{j a m})$ & $\boldsymbol{C}_{\boldsymbol{g} a \boldsymbol{b}}$ & $\boldsymbol{A}\left(\mathbf{k m}^{\mathbf{2}}\right)$ & $\boldsymbol{I}(\mathbf{m m} / \mathbf{j a m})$ & $\boldsymbol{Q}_{\text {hidrologi }}\left(\mathbf{m}^{\mathbf{3}} \mathbf{\mathbf { d t }}\right)$ \\
\hline TK.A6-TK.A7 & SP.A1 & 0,080 & 0,780 & 0,0027 & 325,570 & 0,190 \\
TK.A7 & SP.A12 & 0,110 & 0,791 & 0,0034 & 264,178 & 0,200 \\
BK.A5-BK.A6 & SP.A2 & 0,220 & 0,880 & 0,0031 & 169,606 & 0,130 \\
BK.A6-TK.A17 & SP.A21 & 0,240 & 0,890 & 0,0033 & 160,797 & 0,130 \\
TK.A17-BK.A8 & SP.A22 & 0,240 & 0,890 & 0,0034 & 160,157 & 0,130 \\
TK.B12-TK.C1 & SP.B & 0,140 & 0,900 & 0,0054 & 224,256 & 0,300 \\
\hline
\end{tabular}

Sumber: Hasil Analisis, 2020

Hasil analisis hidrologi pada masing-masing saluran kemudian akan dibandingkan dengan besar kapasitas saluran eksisting kawasan Fakultas MIPA ITK untuk mengetahui kapasitas saluran masih dapat memfasilitasi debit hidrologi yang mengalir pada saluran.

\subsection{Analisis Hidrolika}

Analisis hidrolika berfungsi untuk mengetahui kapasitas dari suatu penampang saluran. Kapasitas dari saluran diketahui dengan membandingkan debit hidrologi yang masuk kedalam saluran dengan kapasitas dari saluran tersebut. Perbandingan debit hidrologi dan kapasitas penampang saluran dapat dilihat pada Tabel 4 berikut:

Tabel 4: Perbandingan debit hidrologi dengan kapasitas saluran Fakultas MIPA ITK

\begin{tabular}{lllllllll}
\hline \multicolumn{1}{c}{ Titik Kontrol } & Saluran & $\begin{array}{c}\boldsymbol{Q}_{\text {hidrologi }} \\
\left(\mathbf{m}^{3} / \mathbf{d t}\right)\end{array}$ & $\begin{array}{c}\boldsymbol{b} \\
(\mathbf{m})\end{array}$ & $\begin{array}{c}\boldsymbol{h} \\
(\mathbf{m})\end{array}$ & $\boldsymbol{d}$ & $\begin{array}{c}\boldsymbol{Q}_{\text {sal }} \\
\left(\mathbf{m}^{3} / \mathbf{d t}\right)\end{array}$ & $\boldsymbol{d e l} \boldsymbol{Q}$ & Ket \\
\hline bk.a1-bk.a2 & st.a1 & 0,018 & 0,25 & 0,3 & - & 0,063 & 0,044 & aman \\
bk.a2-bk.a3 & st.a12 & 0,021 & 0,25 & 0,3 & - & 0,02 & $-0,001$ & meluap \\
tk.a18-tk.a9 & st.a10 & 0,035 & 0,1 & 0,05 & - & 0,006 & $-0,028$ & meluap \\
tk.a9-tk.a6 & st.a8 & 0,028 & 0,3 & 0,4 & - & 0,035 & 0.006 & aman \\
tk.a9-tk.a8 & st.a7 & 0,027 & 0,3 & 0,4 & - & 0,031 & 0,004 & aman \\
tk.a8-tk.a7 & st.a9 & 0,033 & 0,3 & 0,4 & - & 0,043 & 0,010 & aman \\
bk.a1'-bk.a4 & st.a3 & 0,018 & 0,25 & 0,3 & - & 0,02 & 0,001 & aman \\
bk.a4-tk.a12 & st.a31 & 0,032 & - & - & 0,15 & 0,002 & $-0,031$ & meluap \\
tk.a20-tk.14 & st.a4 & 0,061 & 0,3 & 0,4 & - & 0,037 & $-0,024$ & meluap \\
tk.b1-tk.b2 & st.b1 & 0,022 & 0,3 & 0,4 & - & 0,087 & 0,065 & aman \\
tk.b2-tk.b4 & st.b12 & 0,025 & 0,3 & 0,4 & - & 0,037 & 0,012 & aman \\
tk.b3-tk.b4 & st.b13 & 0,009 & 0,3 & 0,2 & - & 0,336 & 0,326 & aman \\
tk.b6-tk.b4 & st.b2 & 0,007 & 0,3 & 0,4 & - & 0,063 & 0,056 & aman \\
tk.b6-tk.b7 & st.b3 & 0,034 & 0,3 & 0,4 & - & 0,034 & $-0,001$ & meluap \\
tk.b7-tk.b8 & st.b31 & 0,043 & - & - & 0,3 & 0,017 & $-0,026$ & meluap \\
tk.b9-tk.b8 & st.b4 & 0,053 & - & - & 0,3 & 0,021 & $-0,032$ & meluap \\
tk.b13-bk.b1 & st.b6 & 0,009 & 0,3 & 0,4 & - & 0,057 & 0,048 & aman \\
tk.b14-bk.b2 & st.b7 & 0,009 & 0,3 & 0,4 & - & 0,065 & 0,056 & aman \\
bk.b2-tk.b12 & st.b71 & 0,038 & 0,3 & 0,45 & - & 0,059 & 0,021 & aman \\
bk.a3-tk.a1 & ss.a1 & 0,041 & 0,4 & 0,6 & - & 0,462 & 0,421 & aman \\
tk.a1-tk.a2 & ss.a12 & 0,041 & 0,4 & 0,2 & 0,3 & 0,028 & $-0,012$ & meluap \\
tk.a2-tk.a3 & ss.a13 & 0,048 & 0,4 & 0,2 & 0,3 & 0,026 & $-0,022$ & meluap \\
\hline
\end{tabular}




\begin{tabular}{lllllllll}
\hline \multicolumn{1}{c}{ Titik Kontrol } & Saluran & $\begin{array}{c}\boldsymbol{Q}_{\text {hidrologi }} \\
\left(\mathbf{m}^{3} / \mathbf{d t}\right)\end{array}$ & $\begin{array}{c}\boldsymbol{b} \\
(\mathbf{m})\end{array}$ & $\begin{array}{c}\boldsymbol{h} \\
(\mathbf{m})\end{array}$ & $\boldsymbol{d}$ & $\begin{array}{c}\boldsymbol{Q}_{\text {sal }} \\
\left(\mathbf{m}^{3} / \mathbf{d t}\right)\end{array}$ & $\boldsymbol{d e l} \boldsymbol{Q}$ & Ket \\
\hline tk.a3-tk.a4 & ss.a14 & 0,049 & 0,4 & 0,2 & 0,3 & 0,032 & $-0,017$ & meluap \\
tk.a4-tk.a5 & ss.a15 & 0,049 & 0,4 & 0,2 & 0,3 & 0,058 & 0,009 & aman \\
tk.a5-tk.a6 & ss.a16 & 0,063 & 0,3 & 0,4 & - & 0,037 & $-0,026$ & meluap \\
tk.a12-tk.13 & ss.a2 & 0,045 & 0,4 & 0,6 & - & 0,092 & 0,047 & aman \\
tk.a13-tk.a4 & ss.a21 & 0,045 & 0,2 & 0,3 & - & 0,015 & $-0,031$ & meluap \\
tk.a14-bk.a5 & ss.a22 & 0,089 & 0,3 & 0,4 & - & 0,087 & $-0,002$ & meluap \\
tk.b4-tk.b5 & ss.b1 & 0,039 & 0,3 & 0,5 & - & 0,292 & 0,253 & aman \\
tk.b8-tk.b10 & ss.b2 & 0,069 & - & - & 0,45 & 0,029 & $-0,040$ & meluap \\
tk.b10-bk.b1 & ss.b3 & 0,143 & 0,4 & 0,55 & - & 1,327 & 1,184 & aman \\
bk.b1-tk.b11 & ss.b4 & 0,149 & 0,5 & 0,75 & - & 0,478 & 0,329 & aman \\
tk.b11-tk.b12 & ss.b5 & 0,208 & 0,5 & 0,7 & - & 0,153 & $-0,055$ & meluap \\
tk.a6-tk.a7 & sp.a1 & 0,190 & 0,5 & 0,6 & - & 0,126 & $-0,062$ & meluap \\
tk.a7 & sp.a12 & 0,200 & 0,3 & 0,4 & - & 0,037 & $-0,163$ & meluap \\
bk.a5-bk.a6 & sp.a2 & 0,130 & 0,6 & 0,8 & - & 0,331 & 0,204 & aman \\
bk.a6-tk.a17 & sp.a21 & 0,130 & 0,6 & 0,8 & - & 0,234 & 0,102 & aman \\
tk.a17-bk.a8 & sp.a22 & 0,130 & 0,6 & 0,8 & - & 0,234 & 0,100 & aman \\
tk.b12-tk.c1 & sp.b & 0,300 & 0,55 & 0,6 & - & 0,82 & 0,516 & aman \\
\hline
\end{tabular}

Sumber: Hasil Analisis, 2020

Berdasarkan hasil tabel di atas, terdapat 2 jenis bentuk saluran eksisting pada Fakultas MIPA ITK yaitu bentuk persegi dan bentuk setengah lingkaran. Bentuk persegi bentuk salurannya menggunakan parameter tinggi $(h)$ dan lebar $(b)$ sementara untuk bentuk setengah lingkaran menggunakan parameter diameter $(d)$. Dari hasil analisis di atas terdapat beberapa saluran dengan nilai debit limpasan yang masuk lebih besar dari nilai debit hidrolika penampang saluran $\left(Q_{\text {hidrologi }}>Q_{\text {hidrolika }}\right)$ yang disebabkan oleh berubahnya fungsi lahan dan meningkatnya nilai koefisien pengaliran $(C$ ) yang berakibat kepada luapan di beberapa saluran pada jaringan drainase kawasan Fakultas MIPA ITK.

\section{Kesimpulan}

Berdasarkan hasil analisis perhitungan, diperoleh kesimpulan sebagai berikut:

1. Berdasarkan perhitungan dengan menggunakan metode rasional besar debit hidrologi pada kawasan Fakultas MIPA ITK memiliki variasi antara $0,007 \mathrm{~m}^{3} /$ detik sampai dengan 0,300 $\mathrm{m}^{3} /$ detik.

2. Berdasarkan analisis hidrolika terdapat 7 saluran tersier, 8 saluran sekunder dan 2 saluran primer yang mengalami kelebihan kapasitas debit sehingga terjadi luapan dengan debit luapan yang bervariasi mulai dari $0,001 \mathrm{~m}^{3} /$ detik hingga $0,163 \mathrm{~m}^{3} /$ detik.

Penelitian dapat dikembangkan dengan menambahkan perencanaan dimensi saluran yang sesuai dengan debit limpasan (hidrologi) setelah kawasan terbangun seluruhnya sebagai alternatif pemecahan permasalahan. Selain itu, perlu dilaksanakan pelebaran dan perbaikan saluran serta badan air (buangan akhir) dari sistem drainase yang sudah ada agar tidak menimbulkan genangan dan atau banjir. 


\section{Daftar Pustaka}

Anggraini (2016) Diktat Hidrolika Saluran, Surabaya: Institut Teknologi Sepuluh Nopember.

Badan Standardisasi Nasional (2016) SNI 2415: Tata Cara Perhitungan Debit Banjir Rencana, Jakarta: Badan Standardisasi Nasional.

Soemarto, C. D. (1999) Hidrologi Teknik, Jakarta: Erlangga.

Suripin (2004) Sistem Drainase Yang Berkelanjutan, Yogyakarta: Andi Offset.

Triadmodjo, B. (2008) Hidrologi Terapan, Yogyakarta: Beta Offset.

Wesli (2008). Drainase Perkotaan, Yogyakarta: Graha Ilmu. 